PREPARED FOR THE U.S. DEPARTMENT OF ENERGY, UNDER CONTRACT DE-AC02-76-CHO-3073

PPPL-2869

PPPL-2869

UC.426

IMPROVEMENT OF TOKAMAK PERFORMANCE BY

INJECTION OF ELECTRONS

BY

M. ONO

DECEMBER, 1992
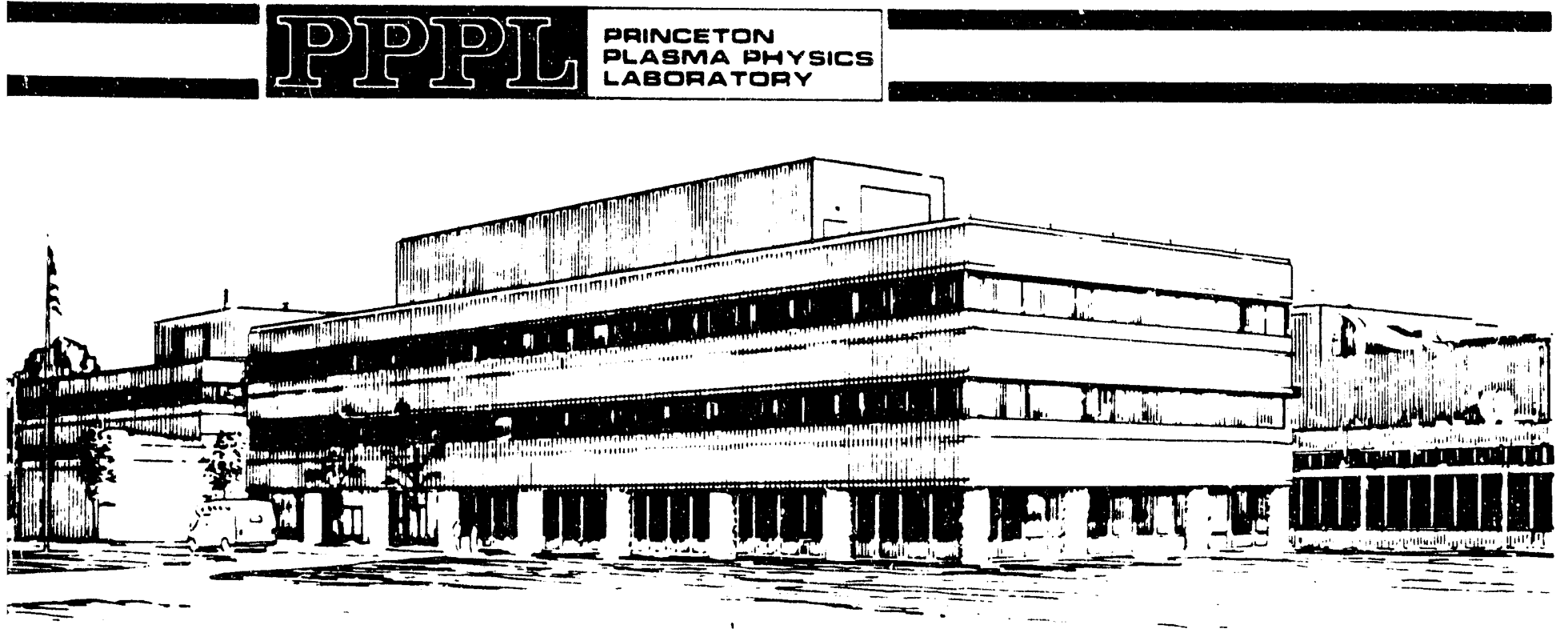


\section{NOTICE}

This report was prepared as an account of work sponsored by an agency of the United States Government. Neither the United States Government nor any agency thereof, nor any of their employees, makes any warranty, express or implied, or assumes any legal liability or responsibility for the accuracy, completeness, or usefulness of any information, apparatus, product, or process disclosed, or represents that its use would not infringe privately owned rights. Reference herein to any specific commercial produce, process, or service by trade name, trademark, manufacturer, or otherwise, does not necessarily constitute or imply its endorsement, recommendation, or favoring by the United States Government or any agency thereof. The views and opinions of authors expressed herein do not necessarily state or reflect those of the United States Government or any agency thereof.

\section{NOTICE}

This report has been reproduced from the best available copy.

Available in paper copy and microfiche.

Number of pages in this report: 24

DOE and DOE contractors can obtain copies of this report from:

Office of Scientific and Technical Information

P.O. Box 62

Oak Ridge, TN 37831 ;

(615) $576-8401$.

This report is publicly available from the:

National Technical Information Service

Department of Commerce 5285 Port Royal Road

Springfield, Virginia 22161

(703) $487-46.50$ 


\title{
Improvement of Tokamak Performance by Injection of Electrons
}

\author{
Masayuki Ono \\ Princeton Plasma Physics Laboratory, Princeton University, P.O. Box 451, Princeton, \\ New Jersey, 08543, USA
}

\begin{abstract}
S
Concepts for improving tokamak performance by utilizing injection of hot electrons are discussed. Motivation of this paper is to introduce the research work being performed in this area and to refer the interested readers to the literature for more detail. The electron injection based concepts presented here have been developed in the CDX (Current Drive Experiment), ${ }^{1}$ CCT (Continuos Current Tokamak), ${ }^{2}$ and CDX-U (Current Drive Experiment-Upgrade) ${ }^{3}$ tokamak facilities. The following three promising application areas of electron injection are described here: 1 . Non-inductive current drive (dc-helicity injection current drive), 2. Plasma preionization for tokamak start-up assist, and 3. Charging-up of tokamak flux surfaces for improved plasma confinement. The main motivation for the dc-helicity injection current drive is in its efficiency that, in theory, is independent of plasma density. This property makes it attractive for driving currents in high density reactor plasmas. The dc-helicity injection was investigated in three devices with rather different device aspect ratios: CDX - I 1 $\mathrm{kA}, \mathrm{q}(\mathrm{a}) \leq 5, \mathrm{R} / \mathrm{a} \approx 15 ; \mathrm{CCT}-\mathrm{I} \leq 6 \mathrm{kA}, \mathrm{q}(\mathrm{a}) \leq 3.5, \mathrm{R} / \mathrm{a} \approx 10 ;$ and $\mathrm{CDX}-\mathrm{U}-\mathrm{I} \leq 10$ $k A, q(a) \leq 8, R / a \approx 2.5$. In $C D X-U$, the ratio of driven to injected current has often exceeded 30, making the effective 'loop-voltage' (the cathode voltage divided by this current multiplication ratio) $\approx 10 \mathrm{~V}$. In the area of tokamak plasma preionzation, utilizing the efficient ionization property of hot electrons, hot electron injection can be used to reduce the tokamak start-up loop-voltage and volt-seconds consumption. This manner of tokamak start-up could be particularly useful in future devices with continuous vacuum vessels, diminishing the current induced in the vessel wall. On CCT, the loop voltage spike was reduced from $\approx 30 \mathrm{~V}$ to $3.5 \mathrm{~V}$ by this hot electron preionization. Another area of potential application would be the tokamak transport improvements (or control) by charging-up the desired flux surfaces. It is of interest to be able to control the plasma transport in tokamak that may make tokamak reactor more economical. As demonstrated in recent years on CCT, the radial electric field is correlated with the $\mathrm{H}$-mode transition. In an emissive limiter-bias experiment, it was found important to inject hot electrons for a good $\mathrm{H}$-mode transition with minimum impurity generation. A new electron injection concept based on ripple trapped electrons is being developed on CDX-U. Electron injection used in this manner could provide a versatile ' $k$ nob' to control the character of transport in tokamak plasmas.
\end{abstract}

\section{Introduction}

Although tokamak is considered to be the leading candidate for a magnetic fusion reactor, it is widely accepted that many improvements are needed for its tconomic viability. It is vital, for example, to find an acceptable method to drive steady-state tokamak current non-inductively and, if possible, to develop a 'knob' to control the plasma transport. In recent years, various concepts for improving tokamak performance by injection of hot electrons have been investigated in the CDX (Current Drive Experiment) ${ }^{1}$ [Phys. Rev. Letters, 59, (1987) 2165.], CCT(Continuous Current Tokamak) $^{2}$ [Phys. Rev. Lett. 63, 2365 (1989)], and CDX-U (Current Drive ExperimentUpgrade) ${ }^{3}$ [Phys. Rev. Lett. 68, 3559 (1992)] tokamak facilities. Injection of hot electrons (few hundred $\mathrm{eV}$ ) using dc-bias supplies has the following attractive features for tokamak applications:

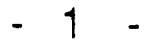


1. Electron injection using relatively low dc-bias voltage is efficient and economical for a given amount of injection power (\$/watt is very low compared to other altemative power sources). This economic efficiency is an important factor when a large power (a significant fraction of reactor output power) is needed in steady-state as in the case for current drive; 2. Due to the naturally high velocity of electrons, electron injection is a good efficient method for injecting a relatively large amount of electrical currents (and magnetic helicity) which is again important for current drive; 3. Hot electrons are an efficient ionizer of plasma; and 4. Since electrons are light, impurity production due to the injection of hot electrons can be moderate (compared to the injections of ions of similar energy due to the mass difference).

To explore the potential application areas for tokamak improvements, a carbon-heated LaB6 (lanthanum hexaboride) cathode has been developed on ACT-1 (Advanced Concepts Torus-1) 4 [Rev. Sci. Instrum. 53, 409 (1982)]] and subsequently used in the CDX, CCT and CDX-U experiments. Through experimental investigations, the following three possible tokamak application areas for hot electron injection have been thus far identified: 1 . Non-inductive current driven by dc-helicity injection, 2 . Tokamak start-up assisted by strong plasma preionization, and 3. Confinement improvements via controlled injection of hot electrons.

For the tokamak non-inductive current drive (dc helicity injection), a low-energy (few hundred $\mathrm{eV}$ ), high-current electron "beam" is used to inject helicity into the plasma and thus, through radial penetration of the injected current, drive bulk steady-state plasma current. 1,5 The beam is injected from a poloidal divertor region to minimize impurity influx and to increase the injected helicity flux. In contrast to high-energy-particle-based current drive schemes, ${ }^{6}$ the efficiencies of which go down linearly with plasma density, the efficiency of helicity-injection current drive is independent of plasma density since most of the current is carried by low-energy electrons, as in ohmic current drive. The efficiency and density independence make this method a particularly attractive candidate for maintaining steady-state current in hot, dense reactor plasmas. On CDX, this approach was successful in creating and maintaining a tokamak plasma without any aid of ohmic heating. 1,7 Due to a relatively high poloidal beta plasma created in the CDX dc-helicity injected plasmas, high beta phenomena were also investigated. 8,9 The encouraging CDX dc-helicity injection experimental result has led to a CDX-CCT collaboration experiment which has successfully driven $6 \mathrm{kA}$ in the CCT tokamak with $\mathrm{q}(\mathrm{a})=3.5 .10 .11$ To extend dc-helicity injection current drive toward more fusion relevant parameters, the CDX-U experiment has been initiated obtaining a $10 \mathrm{kA}$ relatively low aspect-ratio $(\mathrm{R} / \mathrm{a} \approx 2.5)$ tokamak discharge. 12,13 On $\mathrm{CDX}-\mathrm{U}$, the ratio of driven to injected current has often exceeded 30, making the effective 'loop-voltage' (the cathode voltage divided by this current multiplication ratio) $\approx 10 \mathrm{~V}$.

Utilizing that hot electrons (few hundred $\mathrm{eV}$ ) are an efficient producer of plasma, hot electron injection can be used for plasma preionization to reduce the tokamak start-up loop-voltage and voltseconds consumption. This manner of tokamak start-up could be particularly useful in future devices with continuous vacuum vessels, diminishing the current induced in the vessel wall. On $\mathrm{CCT}$, the loop voltage at breakdown was reduced from $\approx 30 \mathrm{~V}$ to $3.5 \mathrm{~V}$ (practically eliminating the voltage spike) by means of electron injection preionization. ${ }^{14}$

Another area of potential application is the tokamak transport improveri ents (or control) by charging-up the desired flux surfaces by injection of electrons. As demonstrated in CCT, a formation of strong radial electric fields is correlated with the H-mode transition. 2,15,16 Electron injection used in this mode could provide a versatile ' $k$ nob' to control the transport in tokamak plasmas that is important for tokamak performance optimization. 


\section{LaB6 Cathode Development}

In order to develop an efficient, clean electron injector, a carbon-heated LaB 6 cathode has been developed on ACT-1.17 The $\mathrm{LaB}_{6}$ cathode has been previously developed for high current ion sources. ${ }^{18} \mathrm{LaB}_{6}$ has a desirable property of high emission current at a relatively low cathode temperature of $\approx 1600^{\circ} \mathrm{C}$ (about $1000^{\circ} \mathrm{C}$ lower than tungsten). Because of the low material evaporation rate at this temperature, the cathode has a relatively long operation life often operating months at a time in hydrogen. $\mathrm{LaB}_{6}$ is relatively resistant to contamination that even if an air leak occurs during the cathode operation, the cathode can recover relatively quickly. The cathode surface can be kept clean by the background ion bombardment from the plasma. LaB 6 has some properties that can make its utilization somewhat more difficult. $\mathrm{LaB}_{6}$ is a metal with a relatively high electrical conductivity that makes it not easy to heat resistively as in the case of tungsten. Therefore, the cathode must be heated indirectly. $\mathrm{LaB}_{6}$ is also chemically reactive at emission temperature that some consideration must be given to the choice of material placed in contact with hot LaB6. A schematic of the CDX cathode is shown in Fig. 1. The CDX cathode uses a carbon heating rod with the $\mathrm{LaB}_{6}$ rings sliding over it. Carbon appears to work well with $\mathrm{LaB}_{6}$ without any sign of deterioration. It is however important to keep the hot carbon from direct exposure to the plasma since the biased hot carbon can erode rapidly. The LaB6 rings are cut to relatively thin slices $(\approx 3 \mathrm{~mm}$ thick) to make it more resistant to thermal fractures. Boron powder is applied on the inner and side surfaces of the $\mathrm{LaB}_{6}$ rings to keep the electrical current from flowing through $\mathrm{LaB}_{6}$ instead of the carbon heater. We find the optimum density of $\mathrm{LaB}_{6}$ to be around $85-90 \%$. If the density is too low (below $80 \%$ ), the cathode tends to crack more easily and if the density is too high (above 90\%), the hardness makes the machining more difficult. We also find that it is difficult to indirectly heat the cathode to a very high emission temperature that is needed for a high current operation. Fortunately, the cathode surface can be heated further from the plasma ion current once plasma can be initiated. For a high current operation, the cathode is initially heated by the carbon heater to produce a modest emission current which creates some plasma. The initiated plasma in turn heats the cathode surface which increases the emission current further. In this way, the cathode current can bootstrap up to a high value. The ultimate current density one can extract from the cathode is usually determined by the plasma density near the cathode (the usual plasma sheath limit). On CDX, the cathode with a few $\mathrm{cm}^{2}$ emission area has emitted current densities of up to $100 \mathrm{~A} / \mathrm{cm}^{2}$ with plasma density of few time $10^{12} \mathrm{~cm}^{-3}$ near the cathode. At present time, a large surface area cathode that would be needed for a high current and/or long pulse operation is under development on CDX-U.

\section{DC-Helicity Injection Current Drive}

Steady-state tokamak operation is considered to be a crucial step toward the achievement of a commercially viable tokamak reactor. RF current drive using lower-hybrid waves ${ }^{7}$ has been quite successful in many experiments. Yet, due to the observed density limit (beyond which the current drive becomes ineffective), relatively low projected efficiency, and possible problems with wave accessibility in reactor-grade plasmas, this approach is considered to be only marginal for tokamak reactors. Wave damping by alpha-particles in an ignited plasma could also hamper rf current drive by preventing penetration of the wave to the plasma core. In yiew of the above problem, an alternative method termed "dc-helicity-injection current drive" has been proposed for driving steady-state tokamak plasma currents. ${ }^{19}$ For dc helicity injection, a low-energy (few hundred eV), high-current electron beam is used to inject helicity into the plasma system and thus, through radial penetration of the injected current, drive bulk steady-state plasma current. 


\section{A. Motivation and Theoretical Background}

The concept of helicity was introduced to fusion research by J. B. Taylor in $1974.20 \mathrm{He}$ proposed that a plasma with a given helicity $\left(\boldsymbol{K} \equiv \int \vee \mathbf{A} \cdot \mathbf{B} \mathrm{dV}\right.$ ), bounded by a conducting shell, would relax toward an equilibrium state of minimum magnetic field energy while conserving the total helicity of the system. This postulate has since been verified on various magnetic configurations including in reversed field pinches, spheromaks, and recently in the CDX tokamak plasma.

From a generalized Ohm's law, Jensen and Chu have derived the helicity balance equation as,

$$
\partial K / \partial t+\int s \mathbf{Q} \cdot \mathbf{n} d S=-2 \int v \eta \mathbf{j} \cdot \mathbf{B} d V
$$

where $\eta$ is the plasma resistivity and $\mathrm{j}$ is the current density. The "Poynting vector" for helicity is

$$
\mathbf{Q}=2 \Phi \mathbf{B}+\mathbf{A} \times \partial \mathbf{A} / \partial \mathrm{t}
$$

and the electric field is

$$
\mathbf{E}=-\partial \mathbf{A} / \partial \mathrm{t}-\nabla \Phi
$$

The volume integral represents the resistive decay of helicity. It is evident that if $Q$ is zero, the term involving resistivity $\eta$ always drives $k$ toward zero. The first term of the flux $Q$ is the $d c$ helicity injection term. For steady-state dc helicity operation, $\partial \mathbf{A} / \partial t=0$ and the time derivative term vanishes and, thus, the dc helicity balance equation becomes

$$
\int_{S} \Phi \mathbf{B} \cdot \mathbf{n} \mathrm{d} S=-\int V \eta \mathbf{J} \cdot \mathbf{B} d V
$$

Therefore, an application of electric potential at points where field lines enter or leave the plasma constitutes one type of $d c$ helicity injection. It should be noted that for tokamak plasma, a predominant toroidal field is already supplied externally, and the helicity injection requirement is relatively small. To inject helicity, the direction of injected current should be the same as that of the main plasma currents.

The helicity injection generates plasma current primarily near the plasma edge; it is necessary for some mechanism to carry this current radially inward. One non-classical current diffusion mechanism is a current-profile-dependent instability. For example, a strong edge current triggers the double-tearing instability only if its direction of flow is parallel to that of the interior plasma currents. Magnetic turbulence associated with the instability can then facilitate the rapid radial penetration of the edge current. This penetration can be modeled by adding to Ohm's law a new term -- one that represents the mean-field behavior of the instability-driven turbulence as an anomalous shear viscosity for parallel electron flow.5,21 This new term results in a modified dchelicity balance equation,

$$
\int S \Phi \mathbf{B} \cdot \mathbf{n} d S-\int S^{\prime} \lambda \nabla\left(J_{\|} / B\right) \cdot \mathbf{n} d S^{\prime}=-\int V \eta \mathbf{J} \cdot \mathbf{B} d V
$$

where $\lambda$ is a positive constant related to the fluctuation level and the second integral term represents the new internal helicity flux term. 
It is possible to simplify further the helicity balance equation, Eq. (2), assuming that the vessel and anode define the zero potential,. Then one obtains

$$
I_{p}=V_{\text {cath }} A_{\text {cath }} B_{\text {cath }} /\left(2 \pi R<\eta>B_{T}\right) .
$$

Here, $\mathrm{V}_{\text {cath }}$ is the potential applied to the cathode, $\mathrm{A}_{\text {cath }}$ is the effective cathode area, and $\mathrm{B}_{\text {cath }}$ is the normal magnetic field at the cathode surface. For the experimental arrangements in CDX, CCT and $C D X-U, B_{\text {cath }}=B_{T}$. In this case, the driven current becomes simply $I_{p}=V_{\text {cath }} A_{\text {cath }} / 2 \pi$ $R<\eta>$ which is independent of magnetic field. The driven current, therefore, goes up with the cathode voltage and the area. Reduction of the average plasma resistivity (hotter plasma) also increases the current. Using Eq. (4,) the helicity balance has been checked experimentally in CDX and CCT.

\section{B. CDX Experiments}

To test the dc-helicity injection as a viable method for tokamak current drive, the first demonstration experiment was conducted on $\mathrm{CDX}^{1}$ The CDX helicity source is a steady-state low energy electron beam emitted by the $\mathrm{LaB}_{6}$ cathode which initially produces a spiraling toroidal current (due to the applied vertical and toroidal fields) and preionizes the plasma as shown in Fig. 2. As the toroidal current is increased, the discharge evolves spontaneously into a circular-shaped tokamak configuration as shown in Fig. 3.1 The spontaneous formation is an evidence of selforganization of the toroidal current system, and it suggests that a preferred state indeed exists even for tokamak. 20 As shown in Fig. 4, the measured poloidal field displays tokamak-like features, reversing near the center of the discharge as expected. The current density and q profiles obtained from this measurement are shown in the inset of Fig. 4. q increases monotonically with the plasma radius, from $q(0)=4$ to $q(a)=10$. The current likewise is peaked at the center which is somewhat surprising in that the current source in this experiment is purely external, a very encouraging result for helicity injection. A comparison of the experimental measurements with the simulation shows the presence of a very strong inward current pinch process, $V_{j} \approx 4$ a/ $\tau_{\text {res }}$ (i.e., the current pinches to the plasma center in a quarter of the resistive time.). Associated with the tokamak formation, the plasma density increases drastically, reaching the chord-averaged density of $\mathrm{n}_{\mathrm{e}}=2 \times 10^{13} \mathrm{~cm}^{-3}$ with a fall-off distance of $3-4 \mathrm{~cm}$ as shown in Fig. 5. The central ion and electron temperatures also go up strongly from a few eV to 15 and $25 \mathrm{eV}$, respectively. The steep profile suggests good particle confinement in this tokamak regime. This improvement in the confinement resulted in a relatively high beta poloidal plasma of $\left\langle B_{\text {pol }}\right\rangle \geq 7.7,8$ Toroidal betas approached Troyon-Sykes beta limit. The current scaling of up to $\mathrm{l} \mathrm{kA}[\mathrm{q}(\mathrm{a}) \approx 4-5]$ has been investigated resulting in a reasonable agreement with the helicity balance equation, Eq. (4), within the experimental uncertainly of about a factor of two.

\section{CCT Experiments}

The encouraging CDX dc-helicity injection experimental result has led to a CDX-CCT collaboration experiment on CCT. The CCT plasmas have typical parameters of $\mathrm{R}=1.5 \mathrm{~m}, \mathrm{a}=$ $0.15 \mathrm{~m}, \mathrm{a}$ (vessel) $=0.4 \mathrm{~m}, \mathrm{~B}_{\mathrm{T}}=0.3 \mathrm{~T}, \mathrm{n}_{\mathrm{e}}=5 \times 10^{12} \mathrm{~cm}^{-3}$ and $\mathrm{T}_{\mathrm{e}}=50 \mathrm{eV}$. Figure 6 depicts several plasma parameters as functions of time for a discharge in CCT with $6 \mathrm{kA}$ of cathode-driven current. The discharge is started by the ohmic heating transformer, and driven to $25 \mathrm{kA}$, after which the transformer is shut off, and the plasma current is allowed to decay until the cathode begins to drive current., At the point where the cathode starts to function, the loop voltage becomes negative, indicating that any (small) ohmic drive thereafter is opposite the direction of current flow. Thus, the effect seen is non-ohmic current drive. In these plasmas, the cathode has 
driven as much as $6 \mathrm{kA}$ of current, corresponding to $\mathrm{q}(\mathrm{a})=3.5$ (noting that the plasma radius for the helicity driven case is smaller than that of the ohmic cases). 10,11 The $6 \mathrm{kA}$ discharge was sustained by $365 \mathrm{~A}$ of injected current at an applied cathode voltage of $400 \mathrm{~V}$, meaning that the injected power was $146 \mathrm{~kW}$. An ohmic discharge of the same resistivity would have required 34 $\mathrm{kW}$ to sustain, so helicity injection drives current at $23 \%$ of the efficiency of ohmic in this case. The characteristic (driven current vs. cathode voltage) observed for the CDX and CCT experiments is shown in Fig. 7. This model fits the data, assuming $\langle\eta\rangle \propto \mathrm{V}_{\text {cath }}{ }^{-1}$, (this scaling assumes that the plasma is getting hotter with higher $V_{\text {cath }}$ ) as shown in Fig. 1. A similar comparison has been made for the C.CT data showing more scatter. In particular, the high current points near $6 \mathrm{kA}$ deviate significantly from the scaling curve. This deviation indicates that the plasma is actually hotter (less resistive) than assumed by the $\langle\eta\rangle \propto \mathrm{V}_{\text {cath }^{-1}}$ scaling.

\section{CDX-U Experiments}

The initial period of dc-helicity injection current drive experiments on CDX-U focused on optimizing the current drive configuration and diagnosing the resulting plasmas. A driven current of up to $10 \mathrm{kA}$ was obtained which corresponds to an estimated edge safety factor of $\mathrm{q}(\mathrm{a}) \approx 8.12,13$ The observed current multiplication factor (ratio of driven current to injected current), which is a measure of current drive efficiency, is quite high, 25-30 (the value was typically 5-6 for CDX). The plasma density tends to increase with plasma current, and the central plasma density of $5 x$ $10^{12} \mathrm{~cm}^{-3}$ has been reached at the highest current. With the newly developed magnetic diagnostics, the actual shapes of the plasma current and iesulting magnetic structure have been reconstructed on $\mathrm{CDX}-\mathrm{U}$ for the first time. ${ }^{12,23}$ Modeling work is now underway to understand the physics of current and helicity diffusion.

\section{Cathode Preionization Experiment on CCT}

For a new generation of tokamaks being built and planned, the chamber is often made with a toroidally continuous wall (without toroidally insulating breaks), due to the vacuum chamber design constraints. With the application of an ohmic heating pulse, a significant amount of eddy currents can be induce in this type of continuous vacuum vessel. The problem with induced eddy currents is most severe in the initiation stage of the discharge when the loop-voltage is high (often called the loop-voltage spike) and plasma current is low. The large induced eddy currents can produce magnetic field errors that would make the tokamak start-up more difficult. Therefore, it is desirable to reduce the loop-voltage spike as much as possible. One way to reduce the loopvoltage spike would be to create a hot target plasma that is already highly conducti.ng. Previously, ECH has been used to create such a target plasma. On CCT, the CDX-U helicity injection cathode was used to inject hot electrons which preionized the plasma, creating highly ionized, high density plasma. In Fig. 8, a comparison of loop-voltage with and without cathode preionization is shown. Using this technique, the loop-voltage spike on the CCT tokamak was reduced from about 35 volts to 3.5 volts, a factor of 10 reduction. No problem with impurities was found. This type of tokamak start-up may be attractive for future devices with continuous vacuum vessel. The lowering of the loop voltage could permit simpler, more reactor compatible vacuum chamber design for future tokamak devices such as ITER. The cathode preionization could also lead to a simpler $\mathrm{OH}$ power supply de ign and possible savings in the $\mathrm{OH}$ coil volt-seconds.

\section{Tokamak Edge Bias Experiments for Transport Improvements}

A new research initiative is the electron ripple injection that is related to the improvement of tokamak confinement. One of the potential problems with $\mathrm{H}$-mode is the required power level for the transition. The empirical scaling from DIIID, for example, suggests that the threshold power goes up with the product of plasma density and toroidal magnetic field. This type of scaling 
suggests that for high density-high field ignition-grade plasmas would require a large power for $\mathrm{H}$ mode transition. Therefore, it is important to understand the trigger mechanism of the $\mathrm{H}$-mode transition and to find a more efficient method that can be used for future devices. On the CCT tokamak, it was demonstrated in detail that an $\mathrm{H}$-mode-like transition can be induced by applying an edge radial electric field (or poloidal rotation) to a tokamak discharge. ${ }^{2,15}$ Recently, the DIIID group has confirmed the correlation between the H-mode transitions (all types) and increased plasma poloidal rotation (and radial electric field) near the plasma edge. ${ }^{16}$ Associated with the transition, a strong modification (and reduction) of microturbulence was also observed. If the radial electric field (as found in the CCT experiment) is the main cause of the transition, there is a hope that the threshold power may be substantially reduced by using a more direct approach. On CCT, only about 20 amperes of radial current was needed to induce an $\mathrm{H}$-mode. Theoretical estimates for larger tokamak plasmas also suggest a similar order of required current that then implies that the actual power required to support such a radial electric field could be relatively modest, even for large fusion devices. These experimental observations are consistent with the theory of plasma bifurcation. Naturally, it would be of interest to invent a tool that can be used to control the radial electric field in a non-intrusive way. We present here two electron injection based methods for inducing $\mathrm{H}$-mode which are being developed on CDX-U and CCT.

\section{A. Edge Injection of Hot Electrons}

One method involves a simple injection of hot electrons at the edge. In the CDX dc-helicity injection experiment, it was discovered somewhat unexpectedly that the dc-helicity driven tokamak has a negative potential well as shown in Fig. 9.8,9 The negative potential well in the plasma creates radial dc electric field and causes the plasma to rotate poloidally with a typical rotation velocity of $1 \times 10^{6} \mathrm{~cm} / \mathrm{sec}$. The radial electric field in the gradient region scales typically as $E_{\mathrm{r}}$ $(\mathrm{V} / \mathrm{cm}) \approx 11 \times \mathrm{B}_{\mathrm{T}}(\mathrm{kG}) / \mu^{0.5}$ where $\mu$ is the mass number of the main plasma ions. The negative potential well created is about $1 / 2$ to $1 / 3$ the value of the cathode voltage. It is conjectured that the hot electrons which can move relatively quickly along the magnetic field line may be diffusing radially inward perhaps due to the stochasticity of the field lines at the edge. This experimental observation suggests that one may be able to create radial electric field region inside plasma (at least by a few $\mathrm{cm}$ ) by just injecting hot electrons from the plasma edge.

On CCT, utilizing the dc-helicity injection cathode as an emissive biasable limiter, an experiment was performed to test if the injection of hot electrons at the plasma edge can induce the H-mode. ${ }^{23}$ This experiment is similar to the previous limiter bias experiments ${ }^{24}$ except that the limiter in this case is an emissive cathode capable of actively injecting electron current. Indeed, it was possible to observe the $\mathrm{H}$-mode transition similar to the method used previously with an inserted hot cathode 2,15 as shown in Fig. 10. The cathode position, cathode bias voltage, and the plasma position were varied. It was found that the plasma position with respect to the cathode is very important in obtaining $\mathrm{H}$-mode plasmas. The emissive cathode must be located near the last closed flux surface in order to charge up the plasma. As the cathode is moved closer to the vessel wall, the positioning of the plasma becomes more sensitive since the plasma can easily detach from the cathode and reattach to the wall, resulting in the termination of $\mathrm{H}$-mode. The emissive capability appears to be important for obtaining a good $\mathrm{H}$-mode transition. With a heated cathode, the transition to $\mathrm{H}$-mode was observed for Vbias $>150 \mathrm{~V}$ and I inj $>30 \mathrm{~A}$ which is an excellent efficiency. The measured radial electric fields suggest that the radial electric field has penetrated a few $\mathrm{cm}$ inside beyond the cathode position.

\section{B. Electron Ripple Injection (ERI) Concept.}

Although the emissive cathode limiter method appears to induce H-mode in CCT, it is important to develop an alternate method that is easier to extrapolate toward larger devices. The hot cathode 
placed near the plasma edge may not be desirable for large device application. In addition, the enhanced radial diffusion of hot electrons is not easy to extrapolate. For this reason, a more controlled non-intrusive means of injecting electrons through ripple fields has been developed by the CDX-U group. 25 The basic idea of electron ripple injection (ERI) is to inject electrons with predominantly perpendicular velocity into a small ripple field and let them grad-B drift into the plasma as shown by a schematic in Fig. 11. Here, the injector (and the ripple field) would be placed at the bottom (or top) of the plasma so that the grad-B drift would carry the electrons into the plasma. The trapped electrons will eventually become detrapped due to collisions, decreasing mirror ratio, and induced poloidal rotation. In this way, one should be able to charge up the plasma interior well inside the last closed flux surface. By changing the ripple field mirror ratio and/or the energy of injected electrons, one can change the location of the potential layer [the DIIID $\mathrm{H}$-mode transition work indicates that the transition (or potential) layer is about $1-3 \mathrm{~cm}$ inside the last closed magnetic surface].

The ripple field is created by bending magnets which causes the magnetic field line to locally bulge outward (toward lower magnetic field) so that electrons with predominantly perpendicular velocity are trapped. The ripple fraction should be kept to minimum to minimize the plasma perturbation as well as the ripple coil stress. The ripple fraction, $d=\left(B_{\max }-B_{\min }\right) /\left(B_{\max }+B_{\min }\right)$, of 0.005 would represent about $1.3 \mathrm{~cm}$ of the field excursion (for TFTR size device) which should be acceptable. To trap the injected electrons in the ripple region, it is necessary to have $V_{\|} / V_{\perp} \leq$ (2 d) $1 / 2$. For example, if $d=0.005$, then $V_{\|} / V_{\perp} \leq 0.1$. It is, therefore, important to come up with a scheme to inject electrons with predominantly perpendicular velocity into the ripple region. Such an injector thilizing ECH is being developed by the CDX-U group.

Possible acivantage of ERI concept is that the physics of ERI is relatively simple that, if successful, the methoo san be extrapolated to the future devices with a high level of confidence. The theoretical calculations indicate that, from the kinetic instability point of view, the physics of electron ripple injection can be considered classical. As an initial step, a proto-type electron ripple injector will be tested on CDX-U. If successful, this method will be extended on the CCT tokamak for a demonstration experiment.

\section{Conclusions}

Concepts for improving tokamak performance by injection of electrons developed on CDX, CCT, and $C D X-U$ have been summarized. Injection of electrons lising dc-bias supplies has many attractive features for tokamak applications: 1. Electron injection using dc-bias is efficient and economical for a given amount of injection power; 2. Due to the naturally high velocity of electrons, electron injection is a good method for injecting a relatively large amount of currents; 3 Hot electrons are an efficient ionizer of plasmas; and 4. Since electrons are light, impurity production due to the injection of electrons tends to be moderate. To investigate the potential applications for tokamak improvements, a carbon-heated $\mathrm{LaB}_{6}$ (lanthanum hexaboride) cathode has been developed on ACT-1 and subsequently applied in CDX, CCT and CDX-U. Injection of electrons has several potentially useful applications that include tokamak current drive, plasma start-up, and confinement improvements.

In a tokamak divertor configuration, clectron injection (dc-helicity injection current drive) can provide significant non-inductive steady-state toroidal currents. The efficiency of dc-helicity injection, in theory, is independent of plasma density and, thus, it is attractive for driving currents in high density reactor plasmas. The parameters for the dc-helicity injection experiments performed on CDX, CCT and CDX-U were quite different: $C D X-I \approx 1 \mathrm{kA}, \mathrm{R} / \mathrm{a} \approx 15, \mathrm{q}(\mathrm{a}) \approx 5$; $C C T-I \leq 6 \mathrm{kA}, \mathrm{R} / \mathrm{a} \approx 10, \mathrm{q}(\mathrm{a}) \approx 3.5$; and $\mathrm{CDX}-\mathrm{U}-\mathrm{I} \leq 10 \mathrm{kA}, \mathrm{q}(\mathrm{a}) \approx 8, \mathrm{R} / \mathrm{a} \approx 2.5$. On $\mathrm{CDX}-\mathrm{U}$, the ratio of driven to injected current has often exceeded 30 , making the effective 'loop-voltage' 
(the cathode voltage divided by this current multiplication ratio) $\approx 10 \mathrm{~V}$. To further extend the dchelicity injection current drive research further, it is important to develop an advanced cathode system, such as an axisymmetric ring cathode for high current and/or steady-state operation. The axisymmetric ring cathode has a current scaling where $I_{p}$ scales as $a / R^{2} / q(a)$ that is favorable for low-aspect-ratio configuration and for low $q(a)$ or high current operation.

An injection of hot electrons was used to preionize the plasma to reduce the tokamak start-up loopvoltage and volt-seconds consumption. This manner of tokamak start-up could be particularly useful in future devices with continuous vacuum vessels, diminishing the current induced in the vessel wall. On CCT, the loop voltage spike was reduced from $\approx 30 \mathrm{~V}$ to $3.5 \mathrm{~V}$ by means of electron injection preionization.

Another area of potential application would be the tokamak transport improvements (or control) by charging-up the desired flux surfaces. Electron injection used in this mode could provide a versatile 'knob' to control the character of transport in tokamak plasmas. It was demonstrated in $\mathrm{CDX}$ that injection of hot electrons can create the radial electric field inside the plasma. On CCT, hot electron injection was used successfully to obtain a good quality H-mode transition with minimal impurity problem. To extend the concept toward larger devices, an injection scheme based on ripple trapped hot electrons is being develcped by the CDX-U group.

Acknowledgments: The author would like to thank the members of the CDX, CDX-U, CCT groups and others whose published work was referred in this manuscript. He also thanks Dr. T. H. Stix for valuable advice. This work supported by U.S. Department of Energy contract No.

DE-AC02-76-CHO-3073.

\section{References:}

[1] M. Ono, G. J. Greene, D. Darrow, C. Forest, H. Park, and T. H. Stix, Phys. Rev. Letters, 59, (1987) 2165.

[2] J. Taylor, M. L. Brown, B. D. Fried, et al., Hy.ys. Rev. Lett. 63, 2365 (1989).

[3] C.B. Forest, Y.S. Hwang, and M. Ono, Phys. Rev. Lett. 68, 3559 (1992).

[4] K.L. Wong, M. Ono, and G.A. Wurden, Rev. Sci. Instrum. 53, 409 (1982).

[5] T.H. Stix and M. Ono, Princeton University Plasma Physics Laboratory Report PPPL-2211, (1985).

[6] N. J. Fisch, Rev. Mod. Phys. 59, 175 (1987).

[7] M. Ono, D.S. Darrow, G.J. Greene, H.K. Park, and T.H. Stix. 12th International Conference on Plasma Physics and Controlled Nuclear Fusion Research, Nice, France, October 1988, Paper IAEA-CN-50/H-I-1.

[8] M.E. Mauel. T.H. Ivers, H.Y. Che, D. Chen, D. Gates, T.C. Marshall, G.A. Navratil, J. Wang, D.S. Darrow, and M. Ono, 12th International Conference on Plasma Physics and Controlled Nuclear Fusion Research, Nice, France, October 1988, Paper IAEA-CN-50/AVII-6.

[9] D. S. Darrow, Ph.D. Thesis, Princeton University, June 1988.

[10] D. S. Darrow, M. Ono, C. B. Forest, et al., "Properties of de helicity injected tokamak plasmas," Phys. Fluids B 2 (1990) 1415.

[11] D.S. Darrow, C.B. Forest, G.J. Greene, Y.S. Hwang, M. Ono, R.J. Taylor, P.A. Pribyl, J. D. Evans, K.F. Lai, and J. R. Liberati, In Proceedings of the Thirteenth International Conference on Plasma Physics and Controlled Nuclear Fusion Research, Washington DC., USA, October, 1990, (International Atomic Energy Agency, Vienna, Austria), Paper IAEACN-53/E-3-14

[12] Y.-S. Hwang, Ph.D. Thesis, Princeton University, Dec. 1992.

[13] M. Ono, C.B. Forest, Y-S. Hwang, et al., In Proceedings of the 13th International Conference on Plasma Physics and Controlled Nuclear Fusion Research, Wurzburg, 
Germany, October, 1992, (International Atomic Energy Agency, Vienna, Austria), Paper IAEA-CN-56/E-2-5

[14] D.S. Darrow, M. Ono, P.A. Pribyl and R.J. Taylor, in Proceedings of 14 th Symposium of Fusion Engineering, IEEE/NPSS, Oct. 1991.

[15] R.J. Taylor, R. Conn, B. Fried, R. Lehmer, J. Liberati, P.A. Pribyl, L. Schmitz, G. Tynan, B. Wells, D.S. Darrow, , M. Ono, In Proceedings of the 13th International Conference on Plasma Physics and Controlled Nuclear Fusion Research, Washington DC., USA, October, 1990, (International Atomic Energy Agency, Vienna, Austria), Paper IAEA-CN-53/A-6-5

[16] R.J. Groebner, et al., Phys. Rev. Lett.64, 3015 (1990).

[17] J.A. Goree, Ph.D. Thesis, Princeton University, Oct. 1985.

[18] D.M. Goebel, A.T. Forrester, and S. Johnston, Rev. Sci. Instrum. 51, 1468 (1980). Driven Tokamak

[19] T.H. Jensen and M.S. Chu, Phys. Fluids 27, (1984) 2881.

[20] J.B. Taylor, Phys. Rev. Lett. 33, (1974) 1139.

[21] A. H. Boozer, Phys. Fluids 29, 4123 (1986).

[22] Y.-S. Hwang, M. Ono, and D. Darrow, Bull. Am. Phys. Soc. 36, 2443 (1991).

[23] W. Choe, M. Ono, D. Darrow, P.A. Pribyl, J. R. Liberati, and R.J. Taylor, IAEA Technical Committee Meetirs on Tokamak Plasma Biasing, Montreal, Sep. 1992.

[24] See for example, M. Shim A. Ozaki, P. Paterson, et al., J. Nucl. Mater 176-177, 821 (1990).

[25] M. Ono, H. Furth, C. B. Foresi, H. Okuda, and T.H. Stix, US/Japan Workshop on Edge Plasma Modification in Fusion Plasmas, Nagoya, Japan, Jan. (1990). M. Ono, W. Choe, and D. Darrow, LAEA Technical Committee Meeting on Tokamak Plasma Biasing, Montreal, Sep. 1992. 


\section{Figure Captions}

Fig. 1. Detail of the CDX cathode assembly.

Fig. 2. A typical poloidal field config ation of the CDX dc-helicity injection experiment. The projection of field lines into the poloidal plane, showing the influence of the divertor coil upon the lines.

Fig. 3. CDX magnetic field contours in a poloidal cross-section computed by a 2-D numerical simulation code. The toroidal plasma current, IT, is $330 \mathrm{~A}$.

Fig. 4. The poloidal field on the CDX plasma mid-plane, measured by a magnetic probe in a discharge of 330 amperes. $q$ - and j-profiles computed from the poloidal field measurement are shown in the inset.

Fig. 5. Time evolution of the CDX density profile measured by the far-infrared interferometer during the dc-helicity injection experiment. The high current (tokamak) phase start near 110 msec.

Fig. 6. Plasma evolution during a $6 \mathrm{kA}$, cathode sustained plasma in CCT. The plasma startup was performed with the ohmic heating system, after which current was driven by the cathode.

Fig. 7. Driven plasma current vs. voltage for $\mathrm{CDX}$ and CCT dc-helicity injection experiments. The solid circles are data from CDX, the open circles are data from cathode only discharges in CCT, and the solid triangles are data from ohmic startup iischarges in CCT. The solid curves depict scaling based on the helicity balance.

Fig. 8. Cathode preionization. (a) - (c) Normal ohmic discharge with breakdown rf oscillator

- (f) Ohmic discharge with cathode preionization.

Fig. 9 (a) The plasma potential, as measured by the emissive probe in the dc-helicity injected CDX tokamak plasma. The plasma center lies at about $1.5 \mathrm{~cm}$. (b) The poloidal rotation velocity as a function of minor radius computed from the measured potential in Fig. 10(a). The poloidal rotation velocities are similar in all cases within the experimental errors.

Fig. 10. Evolution of plasma parameters of a typical H-mode in C.CT with a heated cathode limiter. Biasing of - $250 \mathrm{~V}$ begins at $39 \mathrm{msec}$ and the transition followed immediately after the biasing.

Fig. 11. A schematic of electron ripple injection set-up. 


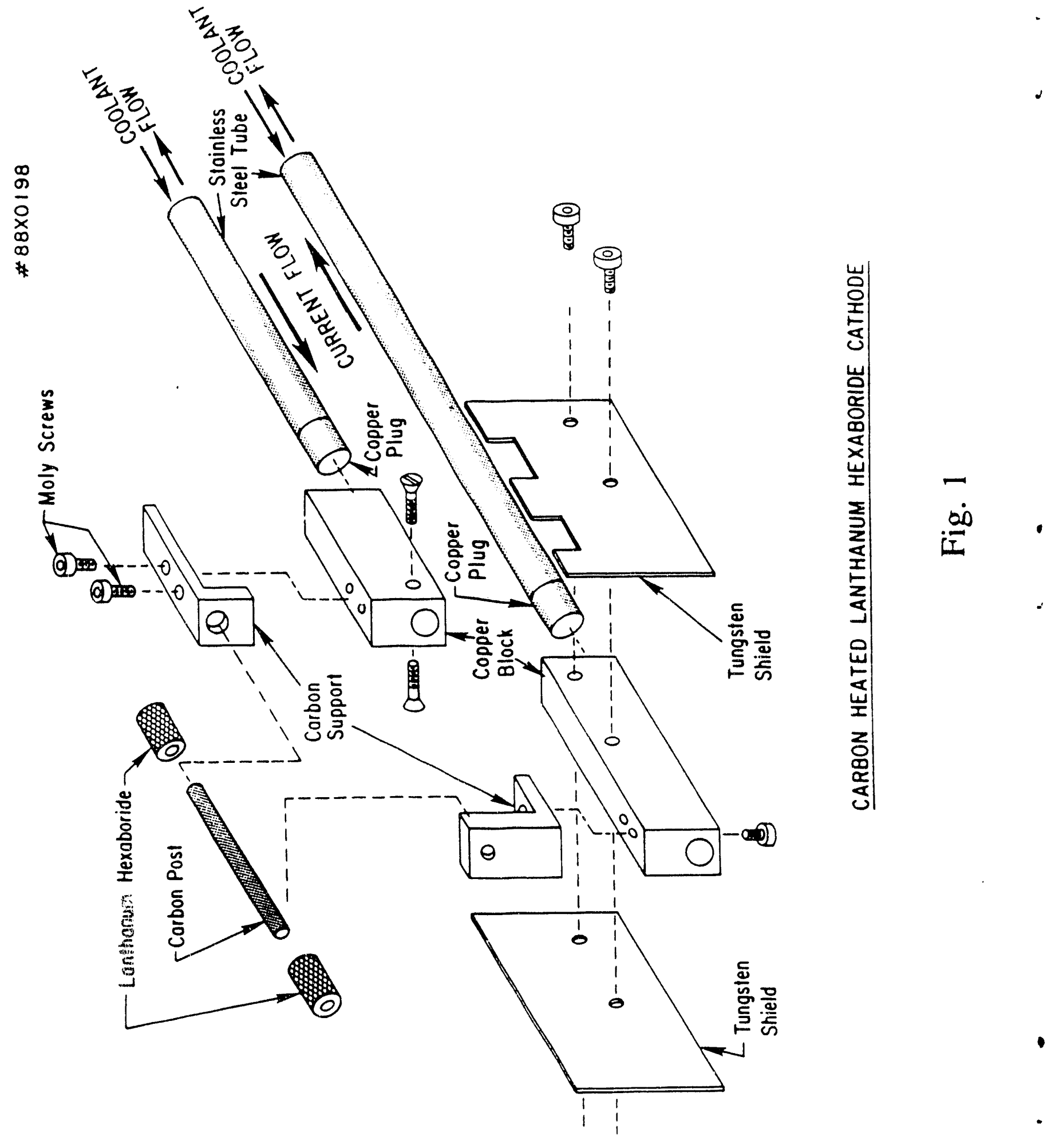




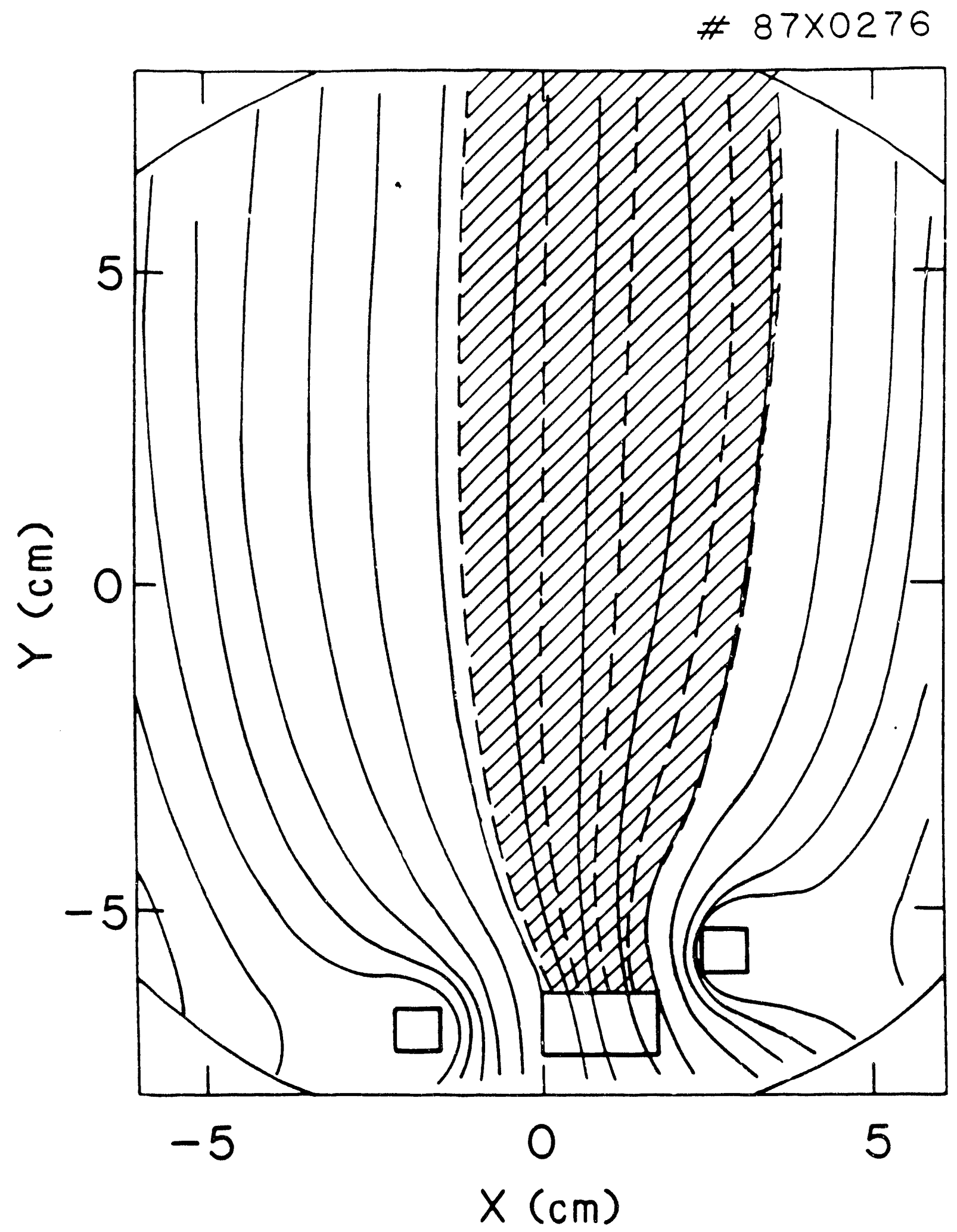

Fig. 2 


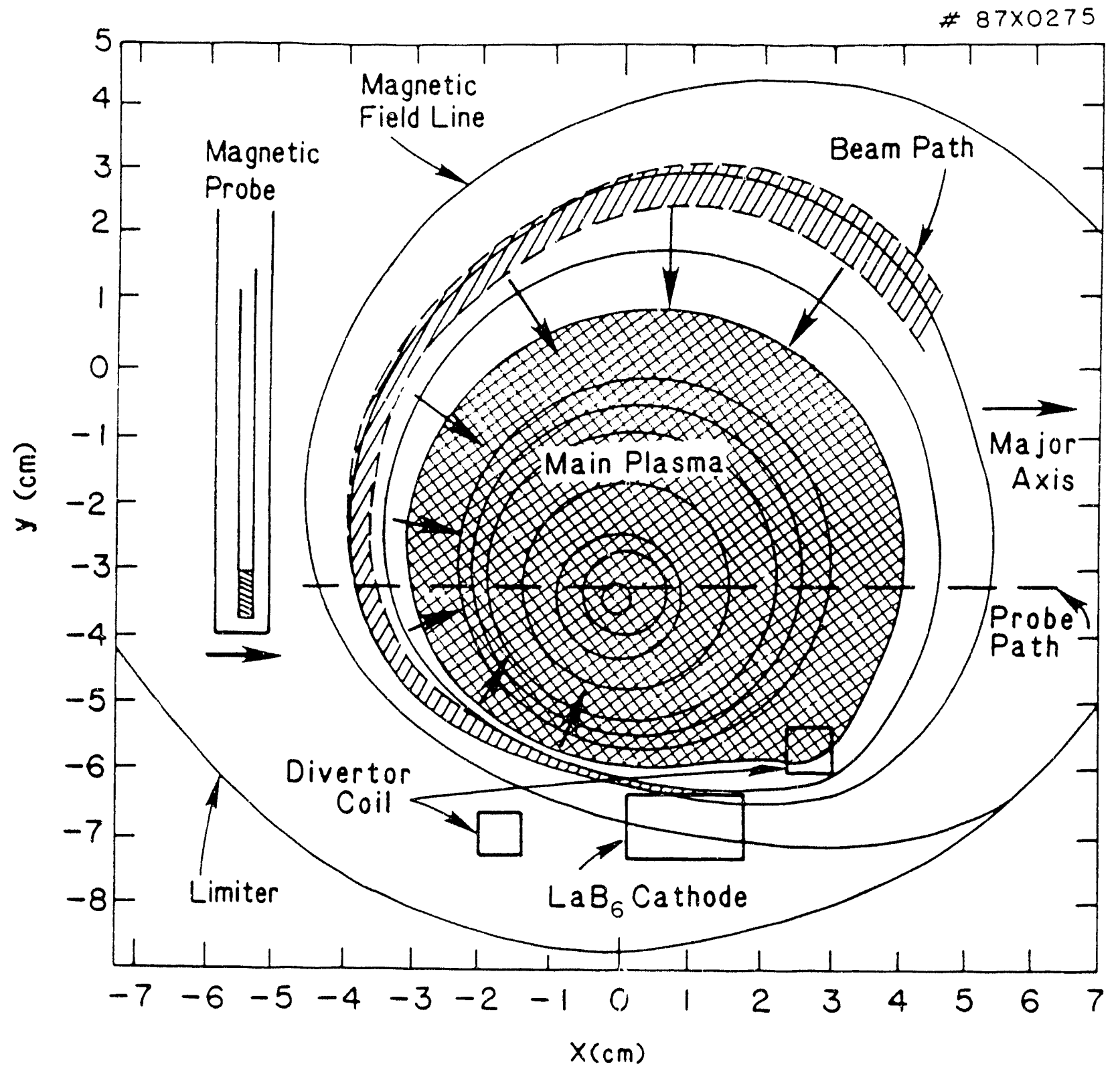

Fig. 3 


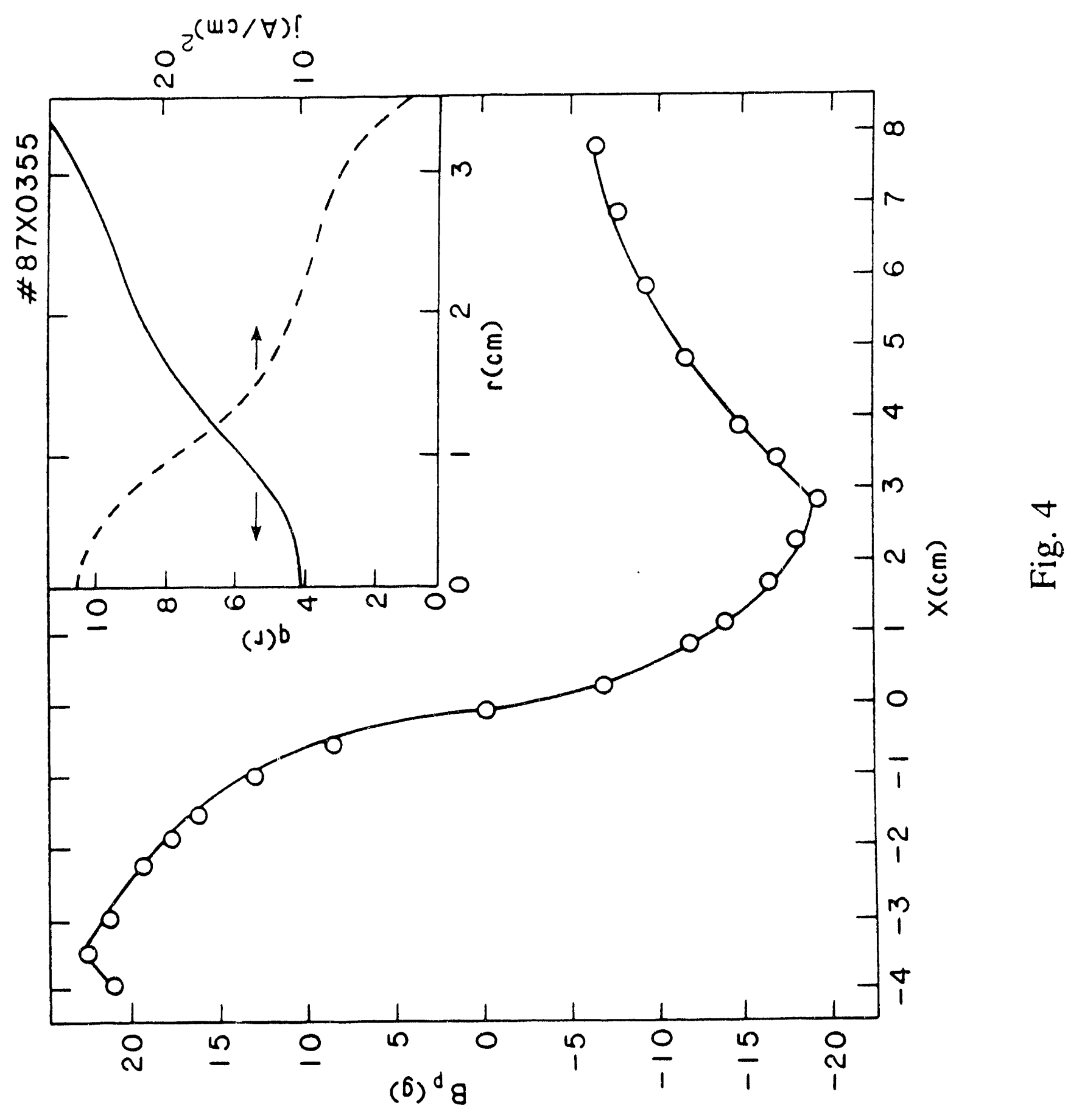




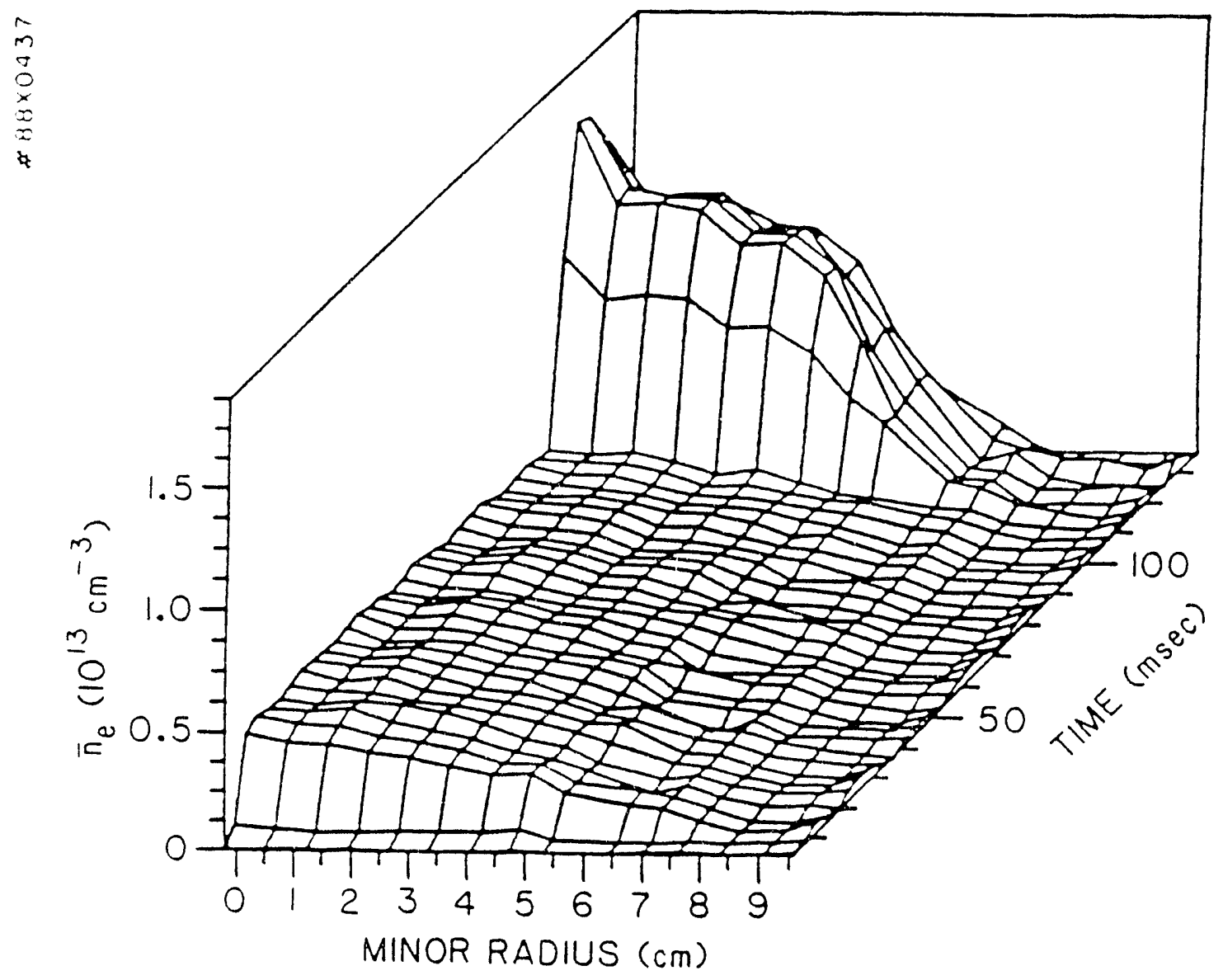

Fig. 5 


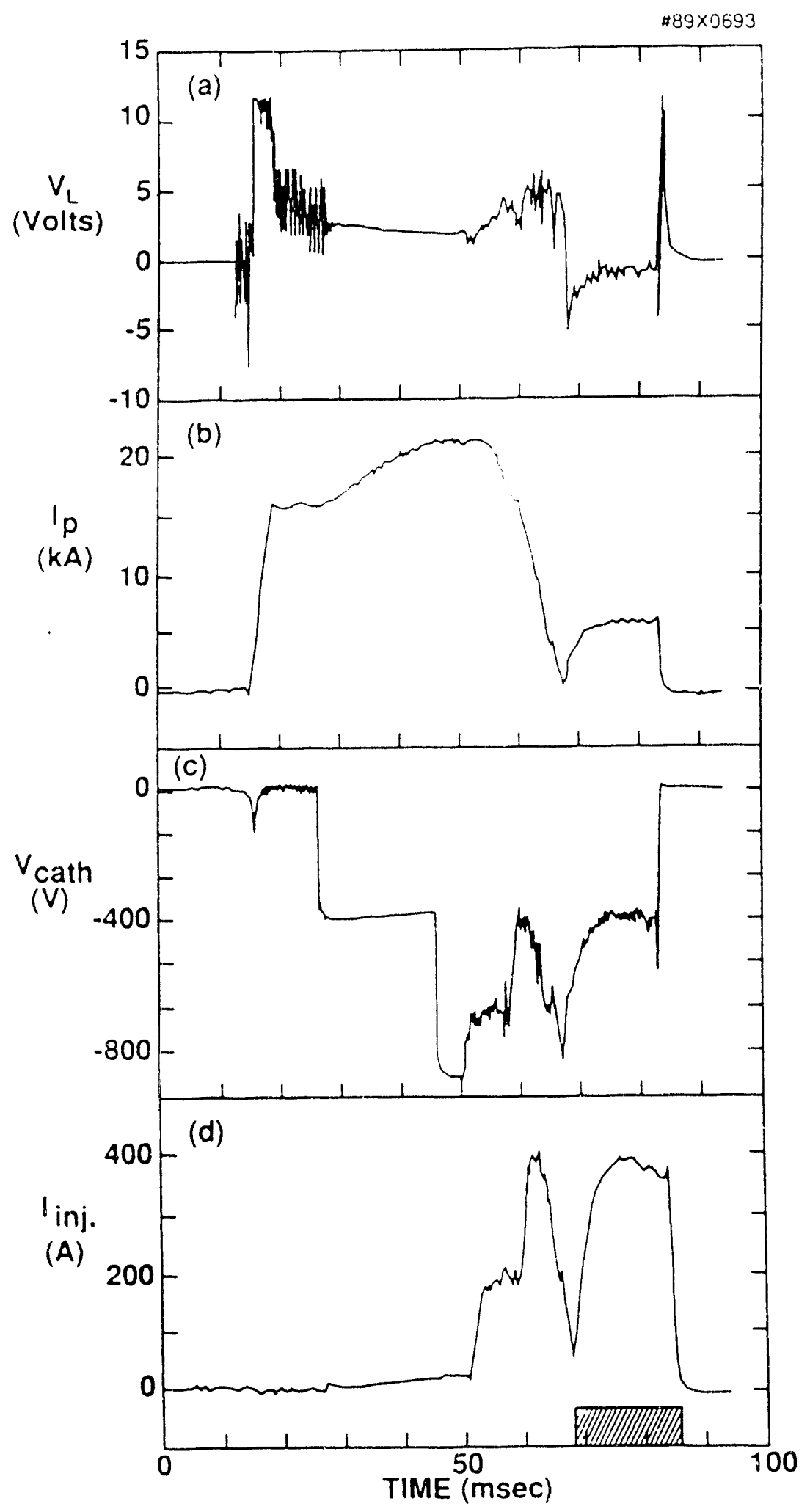

Fig. 6 


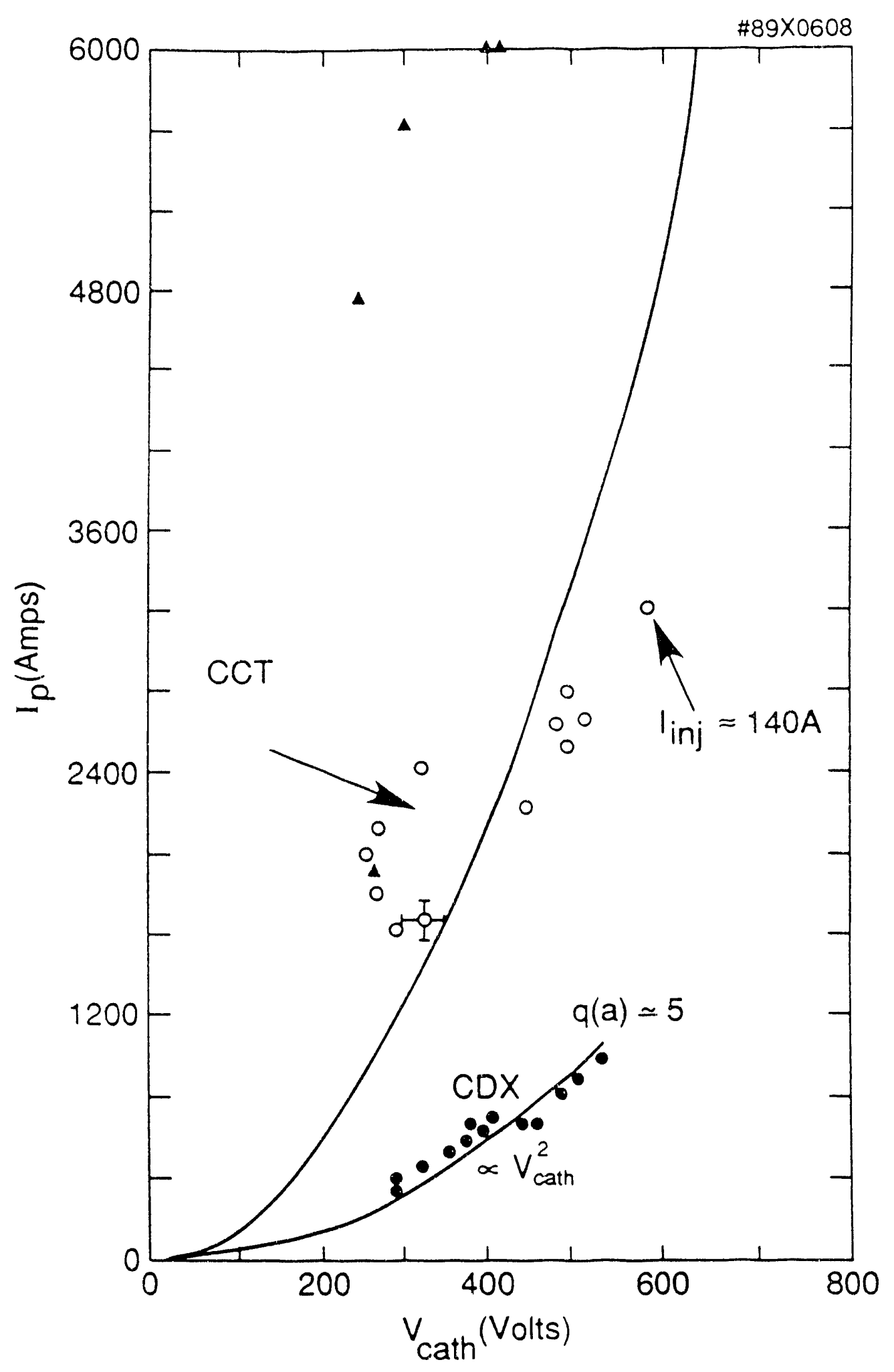

Fig. 7 

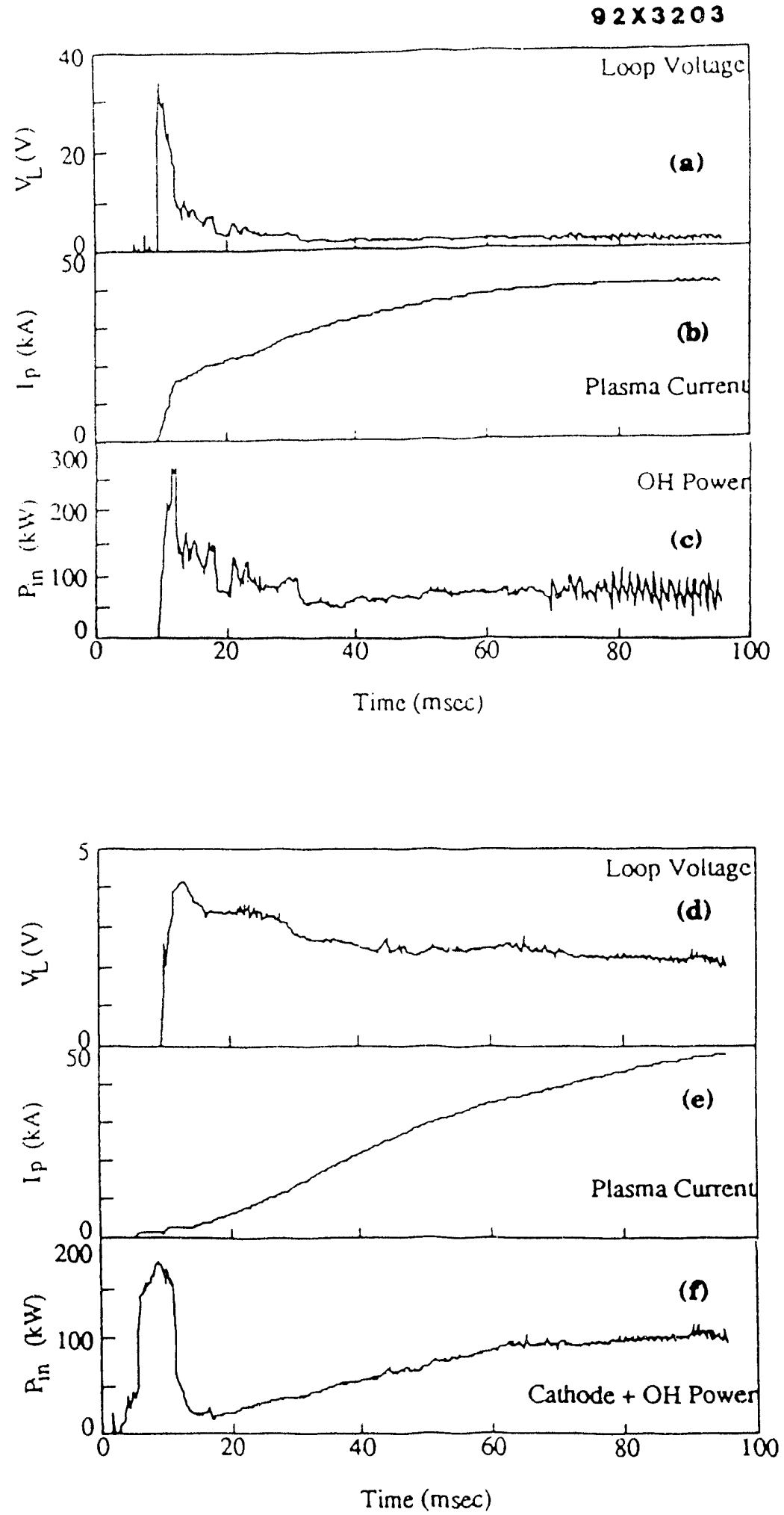

Fig. 8 

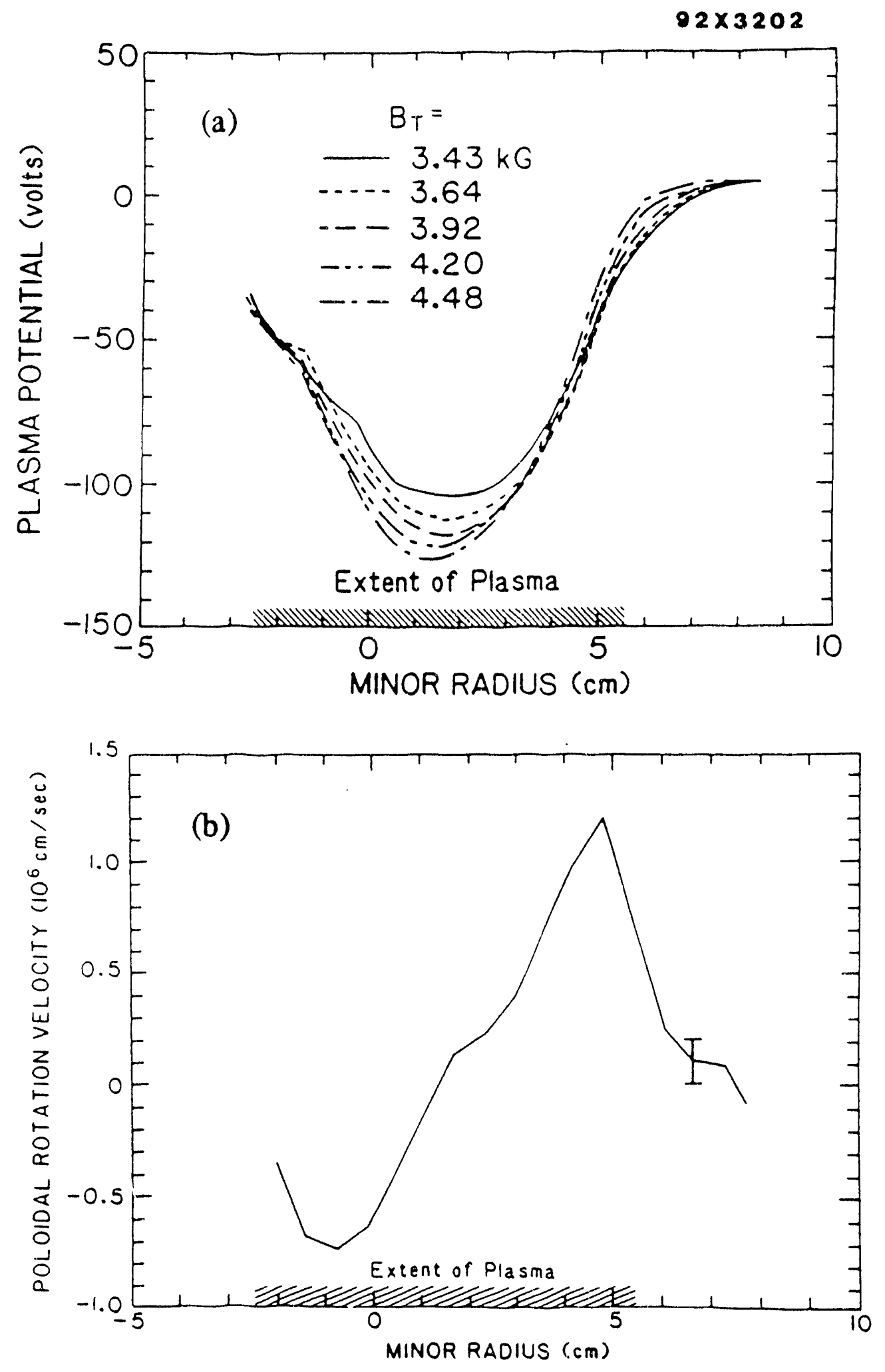

Fig. 9 

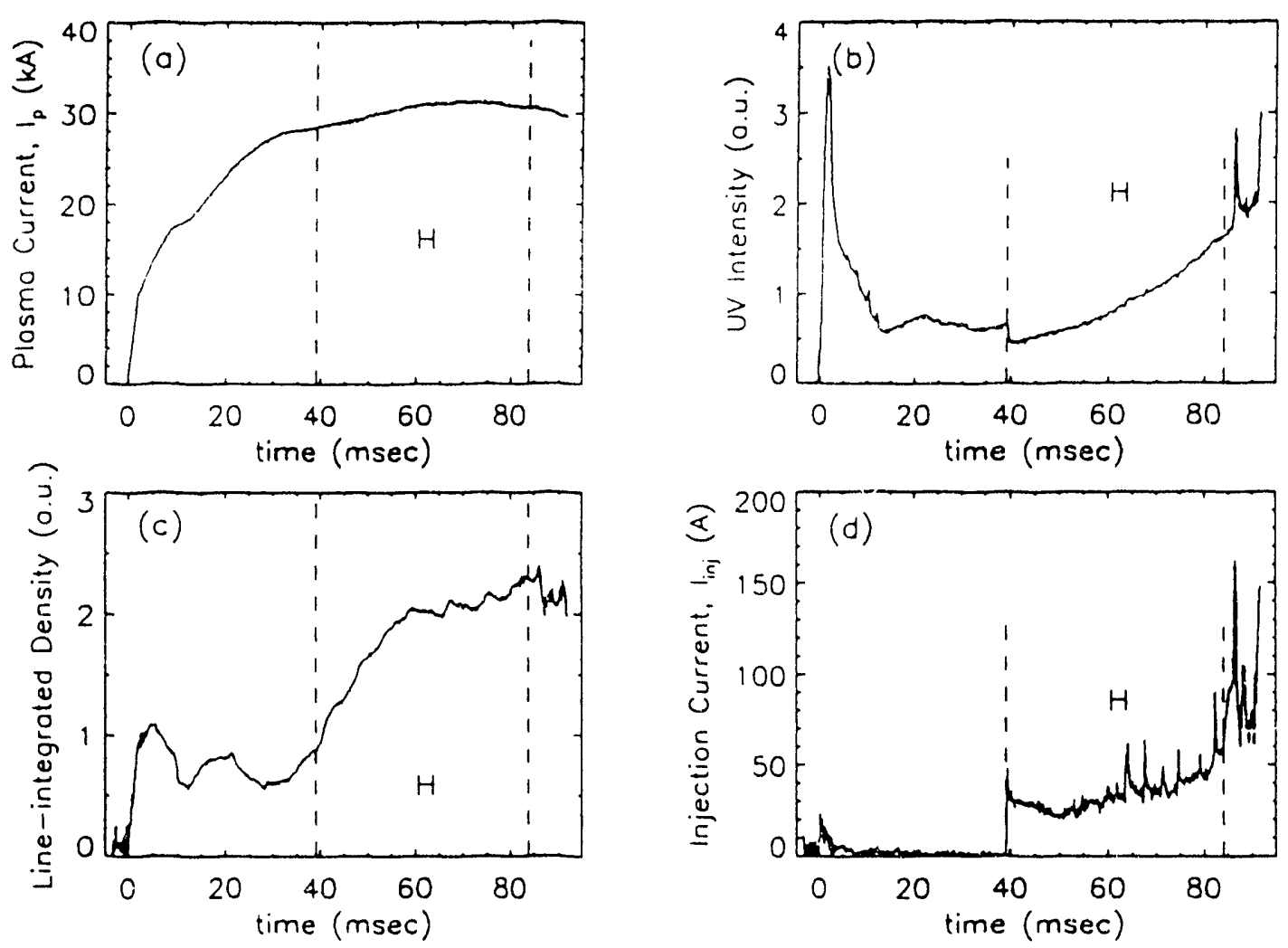

Fig. 10 


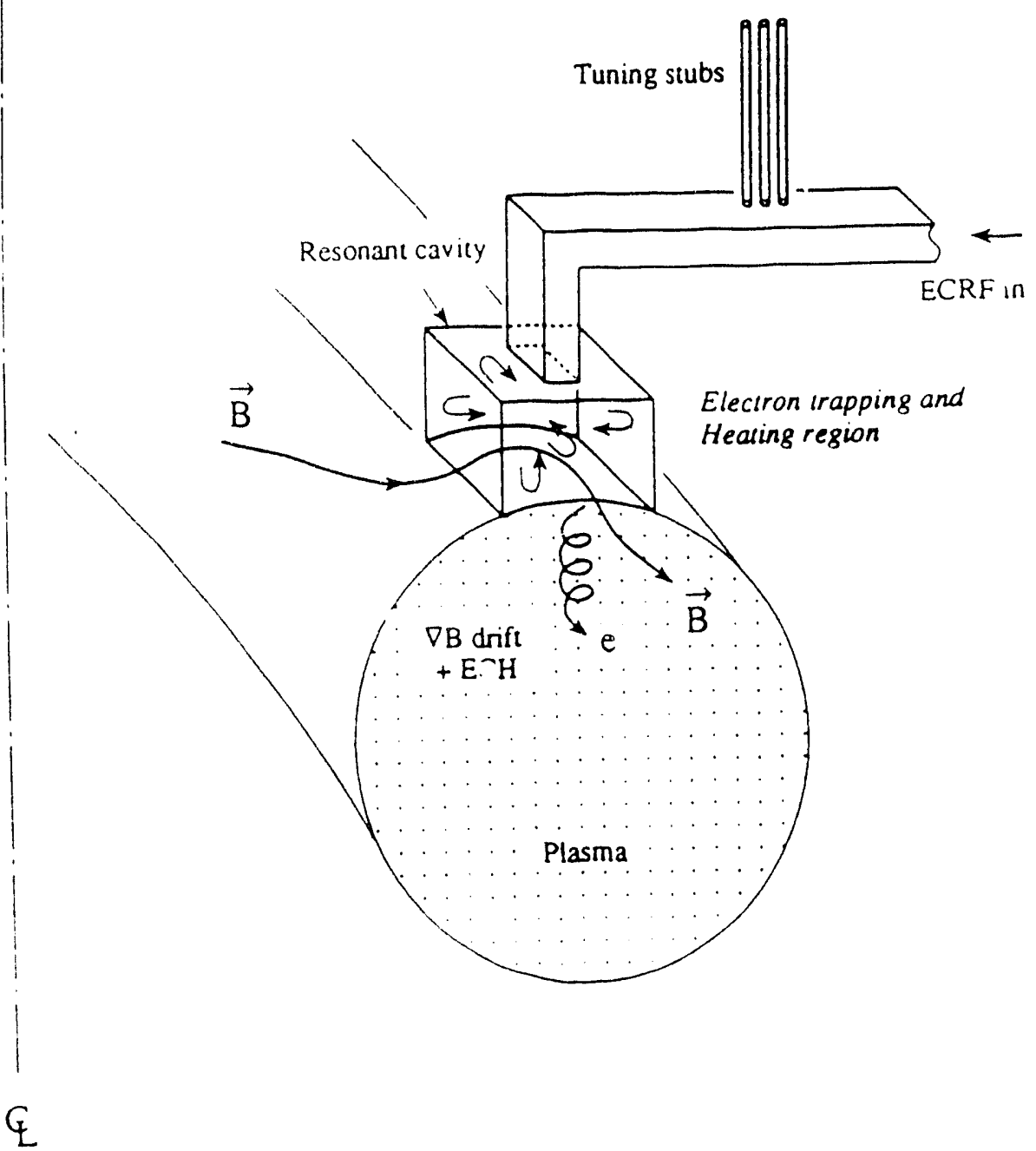

Fig. 11 


\section{EXTERNAL DISTRIBUTION IN ADDITION TO UC-420}

Dr. F. Peoloni, Univ. of Wollongong, AUSTRALIA

Prof. M.H. Brennan, Univ. of Sydnoy, AUSTRALIA

Plaema Posearch Leb., Austratien Nat. Univ., AUSTRALIA

Prot. I.R. Jonos, Flinders Univ. AUSTRALLA

Prof. F. Cep, Inst tor Theoretical Physics, AUSTRIA

Prof. M. Heindier, Instivit for Theorotiecte Physik, AUSTRIA

Prof. M. Gooseons, Astronomiech instiuUt, BELGIUM

Ecole Roy de intituire, Leb. do Phy. Plaemas, BELGIUM

Commission-Europeen, DG. XII-Fusion Proo., BELGIUM

Prot. R. Bouciqus, Rijkeunivervite Gont, BELGIUM

Dr. P.H. Sakenaka, Instituto Fraica, BPUZLL

Instituto Neciond Do Prequizas Especieie-INPE, BPAZIL

Document Oricen, Abonic Enorgy of Cenade Led., CANADA

Dr. M.P. Bectyneki, MPB Technotogios, Inc., CANADA

Dr. H.M. Skarsoard, Univ. of Sackatchowen, CANADA

Prot. J. Teichmam, Univ. of Montreal, CANADA

Prol. S.R. Sroenivesen, Univ. of Colgery, CANAOA

Prot. T.W. Johnston, INRS-Energi, CANADA

Dr. R. Botion, Contre caradien de husion magnótique, CANADA

Dr. C.R. James., Univ. of Nborta, CANAOA

Dr. P. Lukte, Komenetcho Universzitn, CZECHOSLOVAKIA

The Librarien, Cuham Leboretory, ENGLAND

Librery, R61, Ruthertord Appleton Laboratory, ENGLAND

Mrs. S.A. Hutchineon, JET Librery. ENGLAND

Dr. S.C. Shame, Univ. of South Pacific, FWI ISLANDS

P. Mationen, Univ. of Heleinki, FINLAND

Prot. M.N. Busesec, Ecolv Potylechnique,. FRANCE

C. Moutiot, Lob. do Physique Milioux lonises, FRANCE

J. Radol CENCAOARACHE - Bat 506, FRANCE

Prot. E. Economow, Univ. of Crow, GREECE

Ms. C. Pinni, Univ. of loamine, GREECE

Dr. T. Mudi, Acedemy Bibliographic Ser., HONG KONG

Preprint Librery, Huiparian Academy of Sci., HUNGARY

Dr. B. DasGupta, Sana iner of Nucber Ptysics, INDIA

Dr. P. Kaw, Inst. tor Plasma Rosearch, INDIA

Dr. P. Rowenwe, lead Inst of Tectinology, ISPAEL

Librerien, Internationed Conver for Theo Phyaics, ITALY

Miss C. De Palo, Associzione EURATOALENEA, ITALY

Dr. G. Groseo, lstiuto di Fisica ded Plasma, ITALY

Prot. G. Rostangni, istitus Gas lonizzenti Det Cnr, ITALY

Dr. H. Yameto, Tochioa Pees a Dovel Conter, JAPAN
Prot. 1. Kawakemi, Hiroshima Univ., JAPAN

Prof. K. Nishikewwe, Hiroshima Univ., JAPAN

Director, Jepen Atomic Enorgy Rosoarch Inst. JAPAN

Prof. S. Itoh, Kyushu Univ., JAPAN

Reseerch into. Cr., National Instit for Fusion Scienco, JAPAN

Prof. S. Tenake, Kyoto Univ., JAPAN

Library, Kyoto Univ., JAPAN

Prot. N. Inow, Univ. of Tokyo, JAPAN

Socrotary, Plema Section, Electrotecthnica Lab. JAPAN

S. Mori, Tectmical Advieor, LAERI, LAPAN

Dr. O. Midere, Kumemos inat of Techriology, JAPAN

J. Hyoon-Sook, Koree Alomic Enorgy Rosaarch Inst, KOREA

D.I. Chai, The Korea Adv. Inet of Sai. Toch., KOREA

Prot. B.S. Liby. Univ. of Waikato, NEW ZEALAND

inst of Phyrica. Chinose Aand Sa PEOPLE'S REP. OF CHINA

Library, Inst of Plasma Physics, PEOPLE'S REP. OF CHINA

Tringhua Univ. Librey, PEOPLE'S REPUBLIC OF CHINA

Z. L, S.W. Inat Phyeics, PEOPLE'S REPUBLC OF CHINA

Prof. J.A.C. Cobre, Instiuto Superior Tecnico, PORTUGAL

Dr. O. Potrus, Al I CuzA Univ., ROMania

Dr. J. de Villiors. Fusion Studies, AEC, S. AFRICA

Prot. M.A. Helberg. Univ. of Natw, S. AFRICA

Prot. D.E. Km, Pahang Inst. of Sa. \& Tech., SO. KOREA

Prot. C.I.E.MA.T, Fuion Division Library. SPAIN

Dr. L Santio, Univ. of UMEA, SWEDEN

Library, Royd inst. of Tectnology, SWEDEN

Prof. H. Whatmecon, Chaimers Univ. of Tech., SWEDEN

Contre Phys. Des Plasmas, Ecole Potytech, SWITZERLAND

Bibliothed, inst. Voor Plasma-Fysica, THE NETHERLANOS

Aest Prot. Dr. S. Cekir, Middo East Tech. Univ., TURKEY

Dr. V.A. Gulthikh,Sai. Rose. Inst Electrophys. I Apparatus, USSA

D. D.D. Ayubv, Siberian Brench of Academy of Sa., USSA

D. G.A. Eliecov, I.V. Kurchatov Inst, USSA

Librevien. The Ukr.SSA Academy of Sciences, USSA

Dr. LM. Kowrizhnykh, Inst. of Genera Physics, USSR

Kerntorechungsandege GmbH, Zentrabibtionek, W. GERMANY

Bibliothok, Inst For Plasmatorechung. W. GERMANY

Prof. K. Schinder, Ruhr-Univereitu Bochum, W. GERMANY

Dr. F. Weoner. (ASDEX), Max-Planck-Instiut, W. GERMANY

Librarien, Max-Plunck-institur, W. GERMANY

Prof. R.K. Janew, Insel of Prycics, YUGOSLAVIA 

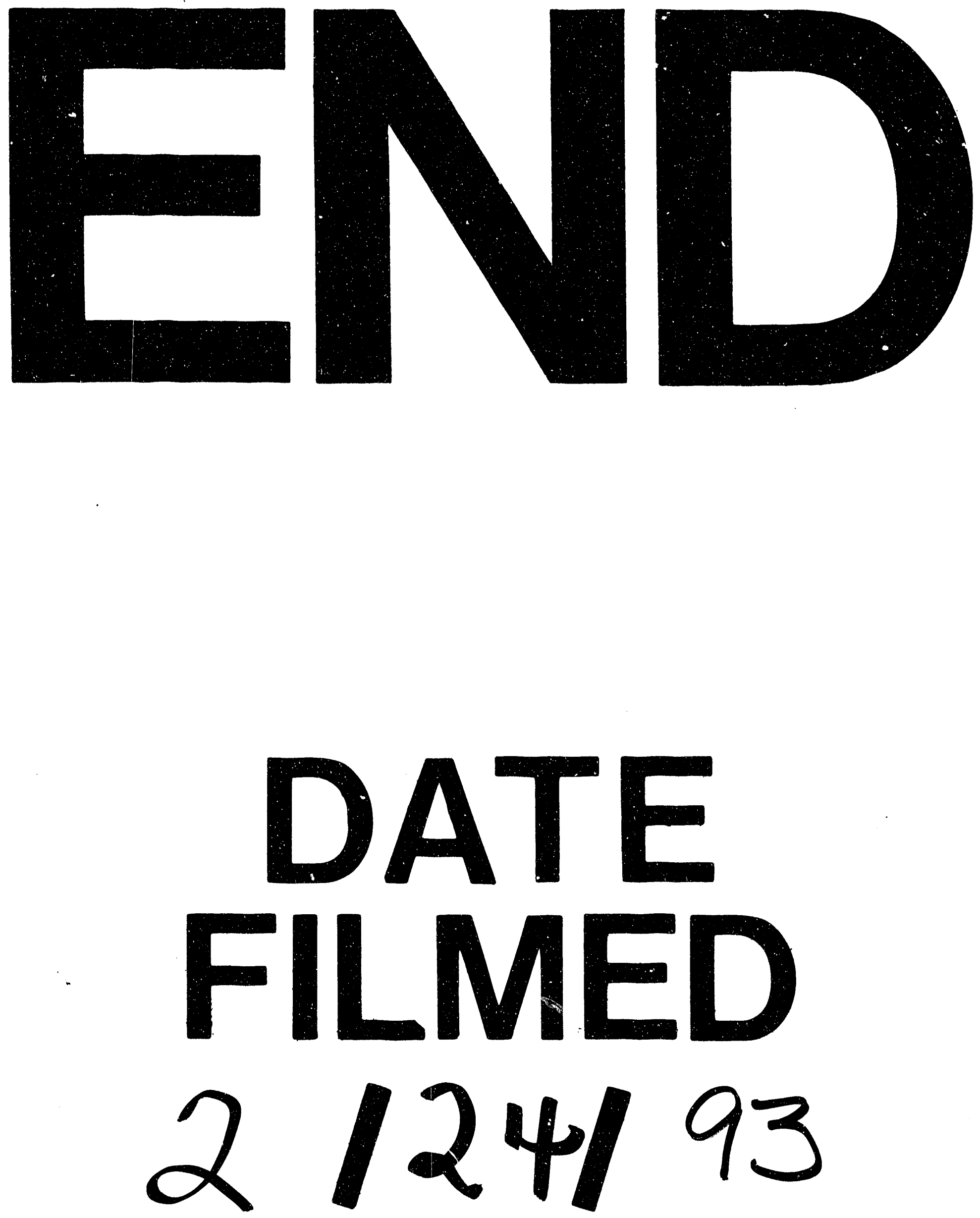
